\title{
Erythroid Cell RNase: Activation by Urea and Localization to the Cell Membrane
}

\author{
EDWARd R. BuRKa \\ From The Cardeza Foundation for Hematologic Research, Department of \\ Medicine, Jefferson Medical College, Philadelphia, Pennsylvania 19107
}

\begin{abstract}
A в S T R A C T Assays of ribonuclease activity in components of mature and immature mammalian erythroid cells indicate that RNase activity is present both in the membrane-free hemolysate and the washed membranes. Erythroid cell RNase exists in an active and latent form. The majority of total cell RNase activity is in the latent state, and is localized to the erythroid cell membrane. Both total and latent RNase activity decline as the cell matures. The latent RNase is released from its relatively firm attachment to the cell membrane and activated by centrifugation or, optimally, by exposure to $4 \mathrm{M}$ urea. The active sites of membrane-associated RNase are apparently oriented toward the inner side of the cell membrane. The properties of the latent membrane-bound RNase which is activated by urea, including $K_{m}, \mathrm{pH}$ optimum, inhibition of enzyme activity by cations, and response to metabolic inhibitors, do not differ significantly from those of the soluble RNase in the membrane-free hemolysate, suggesting that there is only one type of RNase in the erythroid cell. Binding of Rnase to the erythroid cell membrane stabilized the enzyme against inactivation during incubation at $37^{\circ} \mathrm{C}$, and the findings suggest that membrane-bound RNase may play a particular part in degrading ribosomes. The findings indicate that the cell membrane has a major role in RNA metabolism in the maturing mammalian erythroid cell.
\end{abstract}

\section{INTRODUCTION}

The development of the mammalian erythroid element, from nucleated form to reticulocyte to erythrocyte, is accompanied by a progressive loss of ribonucleic acid (RNA) which appears to be closely related to the maturation process $(1,2)$. Since synthesis of RNA is absent in this cell subsequent to the basophilic normoblast state $(1,3,4)$, mechanisms of RNA degradation

Received for publication 3 June 1970 and in revised form 20 August 1970. must play a major part in altering patterns of protein synthesis during cell differentiation and maturation. Although the properties of isolated erythroid cell RNase have been studied $(5,6)$, the factors which influence the action of the enzyme in the intact cell, and which therefore are most relevant to the rate of cell maturation, have been only partially defined (7). The present investigations were designed to provide greater understanding of the mode of action of erythroid cell RNase in the maturing erythroid cell. The results indicate that the majority of RNase activity within the cell exists in a latent state and can be activated by exposure to $4 \mathrm{M}$ urea. The greater portion of latent and total RNase activity, both of which decrease as the erythroid cell matures, is localized to the cell membrane. This latent RNase is particularly effective in degrading ribosomes. The localization of RNase in the cell membrane adds to the evidence that the membrane plays a direct role in erythroid cell RNA metabolism $(7,8)$.

\section{METHODS}

Isolation of cells and preparation of cell components. Peripheral venous blood was obtained from normal New Zealand white rabbits or from animals with a reticulocytosis induced by phenylhydrazine (9). The cells were washed twice with 10 volumes of 310 milliosmolar phosphate buffer, $\mathrm{pH}$ 7.4 , the buffy coat being removed by aspiration after each wash. The cells were lysed by addition of 4 volumes of $7.37 \times$

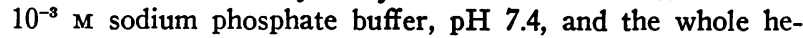
molysates were centrifuged at $17,300 \mathrm{~g}$ for $10 \mathrm{~min}$ in order to separate the cell components. The membrane-free hemolysate was decanted and the membranes were separated by gentle agitation from the hard button of unlysed white cells at the bottom of the tube and washed three times with hypotonic phosphate buffer. This method effectively removes unlysed nucleated cells from the cell components $(6,7)$.

Colloidal silica density gradient centrifugation. Cytoplasmfree membrane structures were obtained by density gradient centrifugation as described by Nilsson and Ronguist (10). Membrane samples were layered on top of a $16 \%(\mathrm{w} / \mathrm{v})$ solution of Ludox HS- 40 and centrifuged for $20 \mathrm{~min}$ at $25,000 \mathrm{rpm}$ in a Spinco SW 25.1 rotor. 
Preparation of ribosomes and $R N A$. Cells from which ribosomes or RNA was to be prepared were washed in $0.9 \%$ sodium chloride which contained $1.5 \times 10^{-8} \mathrm{M}$ magnesium chloride. Ribosomal RNA, soluble RNA, and ribosomes were prepared as previously described (6). ${ }^{32} \mathrm{P}$-labeled and ribosomes were prepared by in vivo labeling as described by DeBellis, Gluck, and Marks (11). Sucrose gradient centrifugation was carried out as previously described (9).

Studies during in vivo aging of erythroid cells. The methods by which cells of progressively greater maturity were obtained from single animals during recovery from a severe phenylhydrazine-induced anemia have been described in detail previously (7).

Assay of ribonuclease activity. Ribonuclease activity in cell components was assayed by degradation of ${ }^{2} \mathrm{P}$-labeled substrates, either RNA or ribosomes, to acid-soluble fragments. The conditions of the assay have been detailed previously (6). Suspensions of cell components were vigorously mixed immediately prior to pipetting. All incubations were carried out under air and with constant agitation. Appropriate zero time controls, with or without the additions described in the text, were obtained with each study. When additions to the assay system were made the amount of reagents and additives in all tubes were adjusted to identical concentrations at the conclusion of incubation. Removal of more than $90 \%$ of the leukocytes from whole blood suspensions by dextran sedimentation prior to preparation of the cell components did not influence the RNase assay.

Analytical methods. Hemocytometry, ennumeration of reticulocytes, and hematocrit determinations were done by standard methods.

Determination of radioactivity. ${ }^{2} \mathrm{P}$ radioactivity was determined by pipetting $0.2-0.5 \mathrm{ml}$ of the solution to be examined directly into $10 \mathrm{ml}$ of Bray's solution (12). Samples were counted to an error of less than $3 \%$ in a Packard liquid scintillation counter with an efficiency of more than 95\%.

Materials. Rabbits were obtained from commercial sources. All chemicals were reagent grade. Carrier-free ${ }^{20} \mathrm{P}$ was obtained from Tracerlab Div., Laboratory for Electronics, Inc., Boston, Mass. Colloidal silica was obtained as Ludox HS-40 from E. I. DuPont de Nemours \& Co., Wilmington, Del.

\section{RESULTS}

The location of RNase in mature and immature erythroid cells. Fig. 1 shows the results of assays of RNase in whole lysates, membrane-free hemolysates (MFH), and isolated washed membranes derived from mature and immature erythroid cells. As explained below, the figures represent the relative distribution of $\mathrm{RNase}$ activity in the cell components in the proportions in which they exist in whole hemolysates. The results define several basic characteristics of RNase activity in mammalian erythroid cells. Firstly, RNase activity declines with cell maturation. The amount of enzyme activity in whole hemolysates of normal blood, with reticulocytosis of $2 \%$, is only $22 \%$ of that in blood with a reticulocytosis of $96 \%$, and thus containing primarily immature cells. Secondly, in both mature and immature cells the major portion of RNase activity is in the MFH, with less than one-third of the total activity being associated with the

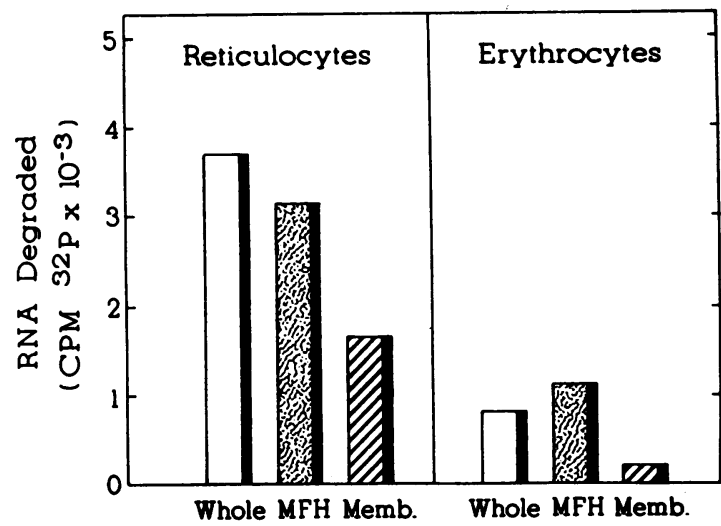

FIGURE 1 RNase activity in whole lysates, isolated membrane-free hemolysates $(\mathrm{MFH})$, and washed membranes prepared from immature and mature erythroid cells. The immature cells consisted of $96 \%$ reticulocytes and the mature cells, $2 \%$ reticulocytes. The results are expressed as cpm of $80 \mu \mathrm{g} / \mathrm{ml}$ of ${ }^{22} \mathrm{P}$ reticulocyte RNA degraded to acid-soluble nucleotide during a $1 \mathrm{hr}$ incubation at $37^{\circ} \mathrm{C}$. The proportion of the total substrate degraded by the whole lysates of reticulocytes and erythrocytes was 32 and $7 \%$, respectively.

isolated washed membranes. Thirdly, since the sum of RNase activities in the separated components exceeds that of the whole hemolysate, there is activation of RNase activity during separation of the cell components. This last finding suggested that RNase activity within the erythroid cell might be affected by inhibitors or that a portion of the Rnase within the cell might exist in a latent state.

Hemoglobin has been reported to inhibit the activity of an RNase isolated from mammalian reticulocytes (5). Since the activity of the isolated MFH in itself often exceeded that of whole hemolysate (Fig. 1, right), it appeared unlikely that the removal of hemoglobin from isolated membranes during the separation procedure was responsible for the activation of RNase. This possibility was directly tested by adding graded amounts of membrane-free hemolysate, aged for 4 wk at room temperature and shown to be devoid of RNase activity, to washed cell membranes prior to assay for RNase activity. The RNase activity in the membrane did not decrease in the presence of increasing amounts of hemolysate, indicating that removal of a soluble component in the hemolysate is not responsible for the activation of RNase which occurs when erythroid cell components are separated.

The possibility that the RNase activity of erythroid cell membranes was derived from free RNase, which in some manner became associated with the membrane during the separation procedure, was tested by determining whether exposure of purified washed membranes to fresh $\mathrm{MFH}$ resulted in increased enzyme activity of the membranes. Following incubation of isolated erythrocyte or reticulocyte membranes with various amounts of fresh $\mathrm{MFH}$ 


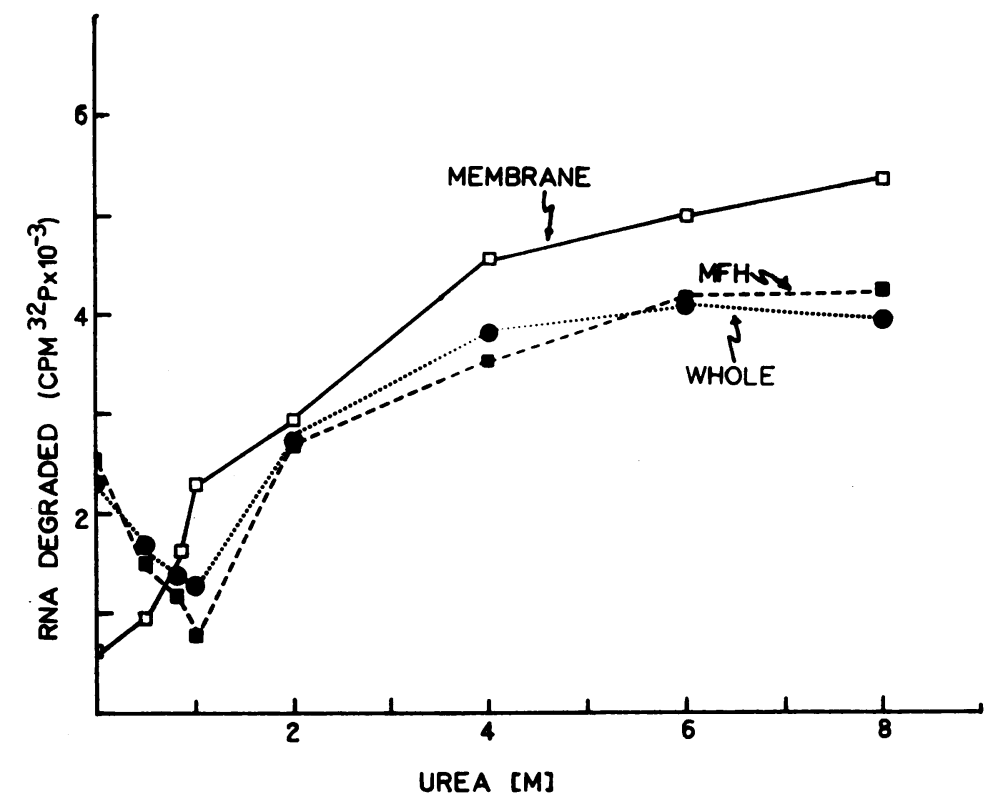

Figure 2 The effect of urea on the degradation of RNA by whole lysate and isolated cell components of erythroid cells. RNase activity is expressed as cpm of $84 \mu \mathrm{g} / \mathrm{ml}$ of ${ }^{\approx 2} \mathrm{P}$ ribosomal RNA degraded to acid-soluble fragments during a $1 \mathrm{hr}$ incubation at $37^{\circ} \mathrm{C}$. The assays, containing concentrations of urea up to 8 moles/liter, were carried out as described in the Methods section. The maximal degradation illustrated represents solubilization of $82 \%$ of the substrate.

at $37^{\circ} \mathrm{C}$ for $30 \mathrm{~min}$, enzyme activity in the subsequently separated membrane fraction was not increased, whether or not urea was present (see below). In order to further confirm that enzyme activity was intimately associated with the membrane, a membrane preparation devoid of cytoplasmic structures was obtained by density gradient centrifugation in a colloidal silica solution (10). RNase activity was present in this highly purified membrane fraction. The data indicate that a true in vivo association exists between RNase and the erythroid cell membrane. Intact erythroid cells did not degrade RNA when the substrate was present in the incubation medium, indicating that the active sites of membrane-associated RNase are oriented towards the interior of the cell.

The activation of erythroid cell RNase by urea. Urea has been used to activate a latent RNase in Eschericia coli (13). The effect of increasing concentrations of urea on RNase activity of whole hemolysate and isolated cell components is shown in Fig. 2. Urea did not affect the RNase activity of the membrane and the MFH in an identical manner. Concentrations of urea less than 1 mole/liter decreased RNase activity in the MFH to a minimum of $32 \%$ of the control value, while higher concentrations of urea increased RNase activity to a maximum of $160 \%$ of the control value. In contrast, all concentrations of urea increased RNase activity in the membrane fraction, in a roughly concentration-dependent manner, to a maximum of 10 times the control value. The effect of urea on RNase activity in whole lysates was that which would be expected from a mixture of the isolated cell components in their naturally existing proportions. Since $4 \mathbf{M}$ urea caused near maximal stimulation

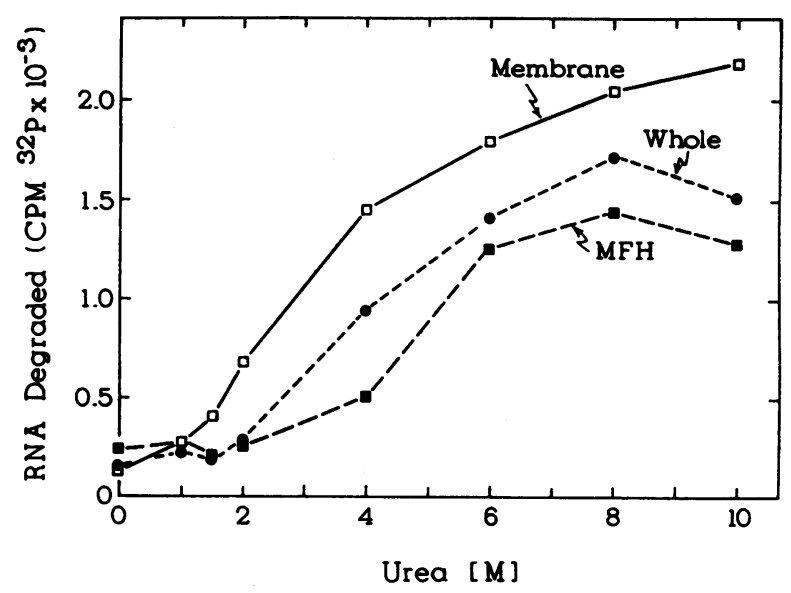

FIgURE 3 The effect of urea on the degradation of ribosomes by whole lysates and isolated cell components of erythroid cells. RNase activity is expressed as cpm of $277 \mu \mathrm{g} / \mathrm{ml}$ of ${ }^{a} \mathrm{P}$ ribosomes degraded to acid-soluble fragments during a $2 \mathrm{hr}$ incubation at $37^{\circ} \mathrm{C}$. The maximal degradation illustrated represents solubilization of $16 \%$ of the substrate. 
of RNase in each of the separated components this concentration was used in all other studies.

The action of urea in increasing the degradation of RNA in the assay system could possibly have been due to an effect on the substrate rather than to activation of RNase. Although comparable concentrations of urea, under the conditions" of the assay, did not degrade ${ }^{2} \mathrm{P}$ reticulocyte RNA to acid-soluble fragments, urea is known to decrease the secondary structure of RNA by breaking hydrogen bonds (14). This effect on RNA structure may make the RNA more susceptible to degradation but if such alterations were the only cause of the observed increase in RNA degradation it would be expected that a like concentration of urea would cause the same increment in degradation by each cell fraction. Examination of Figs. 2 and 3 show this not to be true. Exposure to $1 \mathrm{M}$ urea caused increased substrate degradation in assays of membrane RNase while decreasing substrate degradation in the $\mathrm{MFH}$, and at other concentrations of urea the increase in amount of RNA degradation was not similar in the two cell fractions. These results indicate that although an effect by urea on the substrate cannot be ruled out, it is highly unlikely that urea increases RNase activity only by such an effect. The effect of urea in increasing RNase activity in isolated washed membranes confirms that the activity in membranes does not result from shifting enzyme from the free to the bound state during the preparative procedure.

The solubilization of membrane-bound RNase. It was necessary to determine whether urea increased the RNase activity of the membrane fraction by solubilizing an enzyme which was not fully active when attached to the membrane. When purified membranes, obtained by centrifugation through colloidal silica solutions, were repeatedly washed in $7.37 \times 10^{\circ} \mathrm{M}$ phosphate buffer the activity remaining in the sedimented membranes was decreased by only $11 \%$ (Table I, line 2). Yet, a large amount of RNase, $47 \%$ of the activity present originally in the suspension, was released into the wash fluid from the membranes (line 3 ). This solubilization and activation of RNase when membranes are centrifuged indicates that latent $\mathrm{RNase}$ is present in the membrane fraction and, further, explains the activation of erythroid cell RNase which occurs during the separation of cell components (vide supra). Exposure of membrane fractions to $4 \mathrm{M}$ urea increased the total enzyme activity of the suspension more than fourfold (line 5). Washing the urea-treated membranes resulted in a loss of approximately one-quarter of their RNase activity (line 6 ). The wash fluid of the urea-treated membranes contained a large amount of enzyme activity (line 7), and this activity was decreased only by $30 \%$ when the urea was removed by dialysis (line 8 ). This data indicates that some, but not all, of the effect of urea in increasing RNase activity is due to an alteration of the substrate, but that urea also solubilizes and activates a membranebound RNase. On the basis of the data it is not possible to determine if all of the activation is due to solubilization of the enzyme.

This experiment provides additional evidence that the effect of urea in increasing RNase activity in the membrane fraction cannot be wholly ascribed to an effect of urea on the substrate. When wash fluid derived from membranes which were not exposed to urea was made

TABLE I

RNase Activity of Erythroid Cell Membranes before and after Exposure to $4 M$ Urea

\begin{tabular}{cccc}
\hline $\begin{array}{c}\text { Line } \\
\text { number }\end{array}$ & Specimen & R Nase activity \\
\hline & & $c p m s P$ RNA degraded $/$ hr at $37^{\circ} \mathrm{C}$ & \% initial activity \\
1 & Membrane suspension without urea* & 38,025 & 100 \\
2 & Membranes after two washes & 33,842 & 89 \\
3 & Wash fluid & 17,872 & 47 \\
4 & Wash fluid plus 4 M urea $\ddagger$ & 28,413 & 418 \\
5 & Membrane suspension with 4 M urea $\ddagger$ & 158,825 & \\
6 & Membranes after two washes with 4 M urea & 115,942 & \\
7 & Wash fluid & 327,180 & \\
8 & Wash fluid with urea dialyzed away & 219,584 & \\
\hline
\end{tabular}

\footnotetext{
* Purified membrane suspensions, obtained by centrifugation in a $16 \%$ colloidal silica solution (10), were suspended in 20 volumes at $7.37 \times 10^{-8} \mathrm{M}$ phosphate buffer, $\mathrm{pH} 7.4$, in the presence or absence of $4 \mathrm{M}$ urea. After incubation with agitation at $0^{\circ} \mathrm{C}$ for $30 \mathrm{~min}$ the membranes and supernatant were separated by centrifugation at $20,000 \mathrm{~g}$ for $20 \mathrm{~min}$ and assayed for RNase activity as described in Methods.

$\ddagger$ The supernatant, which was obtained from washing membranes without urea, was dialyzed against 1000

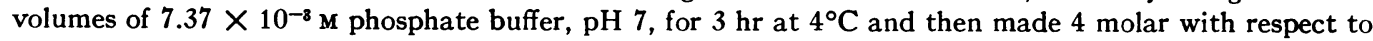
urea prior to assay for RNase.

$\S$ The urea-treated supernatant was dialyzed against two changes of 1000 volumes of $7.37 \times 10^{-3} \mathrm{M}$ phosphate buffer for $3 \mathrm{hr}$ at $4^{\circ} \mathrm{C}$.
} 
4 molar with respect to urea, the RNase activity was increased by about $50 \%$ (compare line 4 to line 3 ). The activity in this case did not, however, approach that found in supernatants derived from urea-treated membranes (line 7 ). This difference between the activity of the two supernatants cannot be ascribed to different effects of urea on the substrate, since the substrate, ${ }^{32} \mathrm{P}$ reticulocyte RNA, was exposed to the identical concentration of urea for the same time in both instances. Although it is difficult, on the basis of the data in lines 7 and 8 , to achieve accurate figures, a conservative estimate allows that at least half of the increased RNase activity caused by exposing membranes to urea is due to enzyme activation. In addition, when supernatants derived from urea-treated membranes were dialyzed against phosphate buffer to remove the urea, the RNase activity in the supernatants (line 8) was still significantly higher than that found in similarly treated supernatants derived from membranes which had not been treated with urea (line 3 ). The findings indicate that although a portion of the increased RNase activity generated in the presence of urea may be ascribed to substrate alteration, a significant amount of new activity is actually due to RNase activation.

The amount of total enzyme activity in the cell components. In the experimental design the isolated cell membranes were suspended in a volume of buffer equal to that of the $\mathrm{MFH}$. Since $1 \mathrm{ml}$ of membrane suspension contained the absolute amount of membrane from $1 \mathrm{ml}$ of whole hemolysate, it insured that the amount of RNase activity in the isolated components accurately reflected the relative distribution of RNase activity in the whole hemolysates. Urea increased RNase activity in whole lysates and $\mathrm{MFH}$ to approximataely twice the control value. The effect of $4 \mathrm{M}$ urea on isolated membranes was much greater, increasing RNase activity as much as sevenfold. At all concentrations of urea greater than 0.5 mole/liter the RNase activity in the membrane exceeded that of the MFH (Fig. 2). These differences cannot be ascribed to the effect of urea on the substrate, since both cell fractions were exposed to identical urea concentrations for the same period of time. These data indicate that the major portion of total RNase activity in the erythroid cell is associated with the cell membrane, but is demonstrable only after activation by urea.

Characteristics of urea-activated RNase. In order to determine if the latent $\mathrm{RNase}$ in erythroid cell membranes which was activated by urea differed from that which was free in the cell interior, the characteristics of the two enzymes were compared (Table II). The $K_{m}$ of urea-activated membrane RNase, measured against four natural substrates, was not significantly different from that of the free enzyme (6). Other points of similarity between the two enzymes included the relative susceptibility of different natural substrates to degradation, the inhibition of activity by $\mathrm{Mg}^{++}, \mathrm{Ca}^{++}$, and metabolic inhibitors, and the $\mathrm{pH}$ optima in phosphate buffers between $\mathrm{pH} 5.7$ and 8.0 (6). In studies of the $\mathrm{pH}$ optima all membranes were first prepared from cells lysed in $7.37 \times 10^{-3} \mathrm{M}$ phosphate buffer in order to make them equally free of hemoglobin (15). These findings strongly suggest, although they do not prove, that the latent RNase which is activated by urea does not differ from the enzyme active in the absence of urea.

The effect of urea on ribosome degradation. Most of the RNA of the erythroid cell is present in the form of ribosomes, which are less susceptible than soluble RNA to enzymatic degradation by erythroid cell RNase (6). The presence of urea increased degradation of substrate ribosomes by both $\mathrm{MFH}$ and membranes (Fig. 3), but the effect was not quantitatively similar to that observed when the substrate was RNA. Comparison of Fig. 3 with Fig. 2 shows that 4 M urea increased degradation of substrate ribosomes fifteenfold, a much greater effect than the sixfold seen with substrate RNA. Activation of membrane RNase occurred at all urea concentrations but was absent in the $\mathrm{MFH}$ at low urea concentrations. This finding, that similar concentrations of urea cause activation of RNase activity in the membrane fraction and inhibition in the MFH, which suggests that substrate alteration alone cannot explain the observed increase in ribosome degradation, might be the result of increased enzyme activity due to activation of membranebound RNase overbalancing an enzyme inhibition caused

TABLE II

$K_{m}$ of Erythroid Cell RNase in Membrane-Free Hemolysate without Urea (from Reference 6) and in Urea-Treated Membranes

\begin{tabular}{lrrrr}
\hline & \multicolumn{4}{c}{ Substrate } \\
\cline { 2 - 5 } \multicolumn{1}{c}{ RNase derived from } & \multicolumn{1}{c}{ Total RNA } & \multicolumn{1}{c}{ rRNA } & \multicolumn{1}{c}{ sRNA } & Ribosomes \\
\hline Membrane-free hemolysate & $16.7 \times 10^{-8}$ & $12.5 \times 10^{-8}$ & $6.1 \times 10^{-6}$ & $2.0 \times 10^{-6}$ \\
Membrane + 4 M urea & $7.7 \times 10^{-8}$ & $20 \times 10^{-8}$ & $16 \times 10^{-6}$ & $1.0 \times 10^{-6}$
\end{tabular}

The $K_{m}$ in moles per liter was determined as described in reference 6 , assuming the molecular weights of rRNA, sRNA, and ribosomes to be $2 \times 10^{6}, 2.5 \times 10^{4}$, and $4 \times 10^{6}$ respectively. 
by low concentrations of urea (16). Nevertheless, the data indicate that the cell membrane is particularly active in degrading ribosomes.

It was necessary to determine whether the greater susceptibility of ribosomes to degradation by urea-activated RNase, in comparison to RNA, was due to alteration of ribosome structure by urea. Exposure to $4 \mathrm{M}$ urea at $37^{\circ} \mathrm{C}$ for as long as $11 \mathrm{hr}$ did not degrade ribosomes to acid-soluble nucleotides, but did cause polyribosomes to break down to monoribosomes. ${ }^{1}$ Density gradient centrifugation patterns of ribosomes exposed to varying concentrations of urea, and sedimented through gradients containing a similar concentration of urea, indicated that significant breakdown of polyribosomes occurred only at concentrations of urea greater than 1 mole/liter, and all polyribosomes disappeared at concentrations in excess of 2 moles/liter. ${ }^{1}$ Since increased degradation of ribosomes by membranes was observed at concentrations of urea less than 1 mole/liter (Fig. 3), gross alterations in the substrate cannot explain the increased degradation of ribosomes in the presence of urea. In addition, direct examination of degradation of equal amounts of polyribosomes and monoribosomes, isolated from sucrose density gradients, showed them to be equally susceptible to degradation to acid-soluble nucleotides by erythroid cell RNase. Nevertheless, subtle changes in the configuration of the ribosomes, not detectable by gradient centrifugation, cannot be ruled out as a cause for the relatively greater breakdown of ribosomes, as compared to RNA.

The stability of latent RNase. The RNase activity in whole lysates of erythroid cells declines rapidly during incubation at $37^{\circ} \mathrm{C}$, falling to $40 \%$ of the initial level in $24 \mathrm{hr}(6)$. In order to determine whether latent RNase activity declined in a similar fashion, aliquots of $\mathrm{MFH}$ and isolated washed membranes were assayed for RNase activity, in the absence and presence of $4 \mathrm{~m}$ urea, at intervals during incubation at $37^{\circ} \mathrm{C}$ for $24 \mathrm{hr}$. The RNase activity of membrane-free hemolysates declined during the incubation to less than $50 \%$ of the initial level (Fig. 4) and a decline of slightly lesser magnitude occurred when the assays were done in the presence of $4 \mathrm{~m}$ urea. In contrast, RNase activity in membrane, even in the absence of urea, remained stable over the $24 \mathrm{hr}$ period. These results indicate that the RNase activity in the cell membrane, whether or not activated by urea, is in some manner protected from inactivation during incubation at $37^{\circ} \mathrm{C}$.

Bound and free RNase during erythroid cell maturation. The relative activity of free and membrane-associated RNase during erythroid cell maturation was investigated by serially studying blood obtained from an individual animal as it recovered from a severe phenyl-

\footnotetext{
${ }^{1}$ Burka, E. R. Unpublished observations.
}

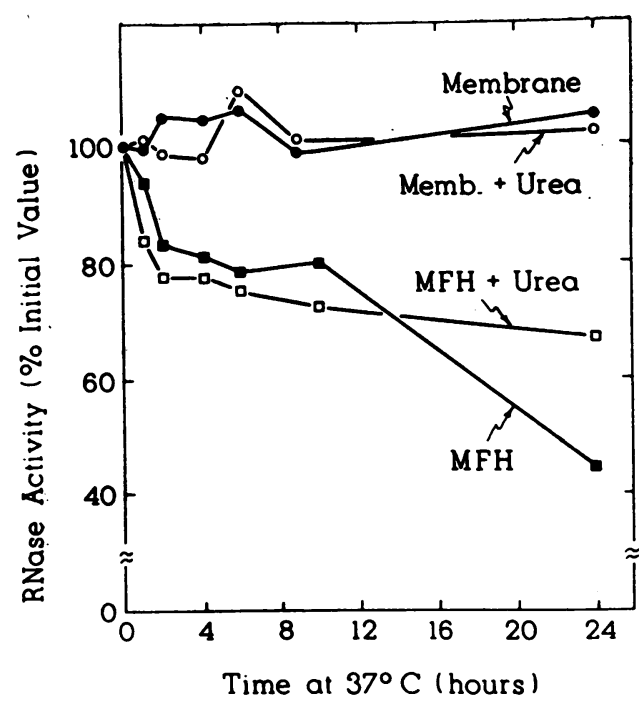

FIgURE 4 The stability of active and latent RNase during incubation of erythroid cell components at $37^{\circ} \mathrm{C}$. Aliquots of the membrane-free hemolysate (MFH) and membrane suspensions were assayed at intervals for RNase activity, as described for Fig. 1, in the absence and presence of $4 \mathrm{M}$ urea. The results are expressed as the per cent of RNase activity present at the start of the incubation. The substrate was $70 \mu \mathrm{g} / \mathrm{ml}$ of ${ }^{32} \mathrm{P}$ total RNA.

hydrazine-induced anemia. During this period the progressive decrease in peripheral blood reticulocytosis reflects a progressively aging population of cells $(7,17)$. Maturation of reticulocytes to erythrocytes was accompanied by a decline in total RNase activity, to approximately one-fifth of the initial value (Fig. 5). The activity in the membrane fraction was $32 \%$ of the total at the beginning of the study and $23 \%$ of the total when the rabbit was hematologically normal. Thus, the activity declined slightly more rapidly in the membrane than in the MFH. Approximately equal activation of RNase occurred during separation of the cell components in both reticulocytes and erythrocytes, to about twice the activity in whole hemolysate. In cells of all ages membrane RNase activity, when measured in the absence of urea, was less than that in the MFH (Fig. 5, lower).

When the latent RNase of the cells was activated by urea the cell membrane had the major portion of enzyme activity in both young and mature cells (Fig. 5, upper). The RNase activity of MFH and whole hemolysate was only slightly affected by presence of urea. The degree of activation in the membranes of both old and young cells was roughly the same, indicating that both active and latent RNase activity decline with cell maturation.

\section{DISCUSSION}

This study provides direct evidence that the cell membrane is the major site of RNase activity in the mam- 


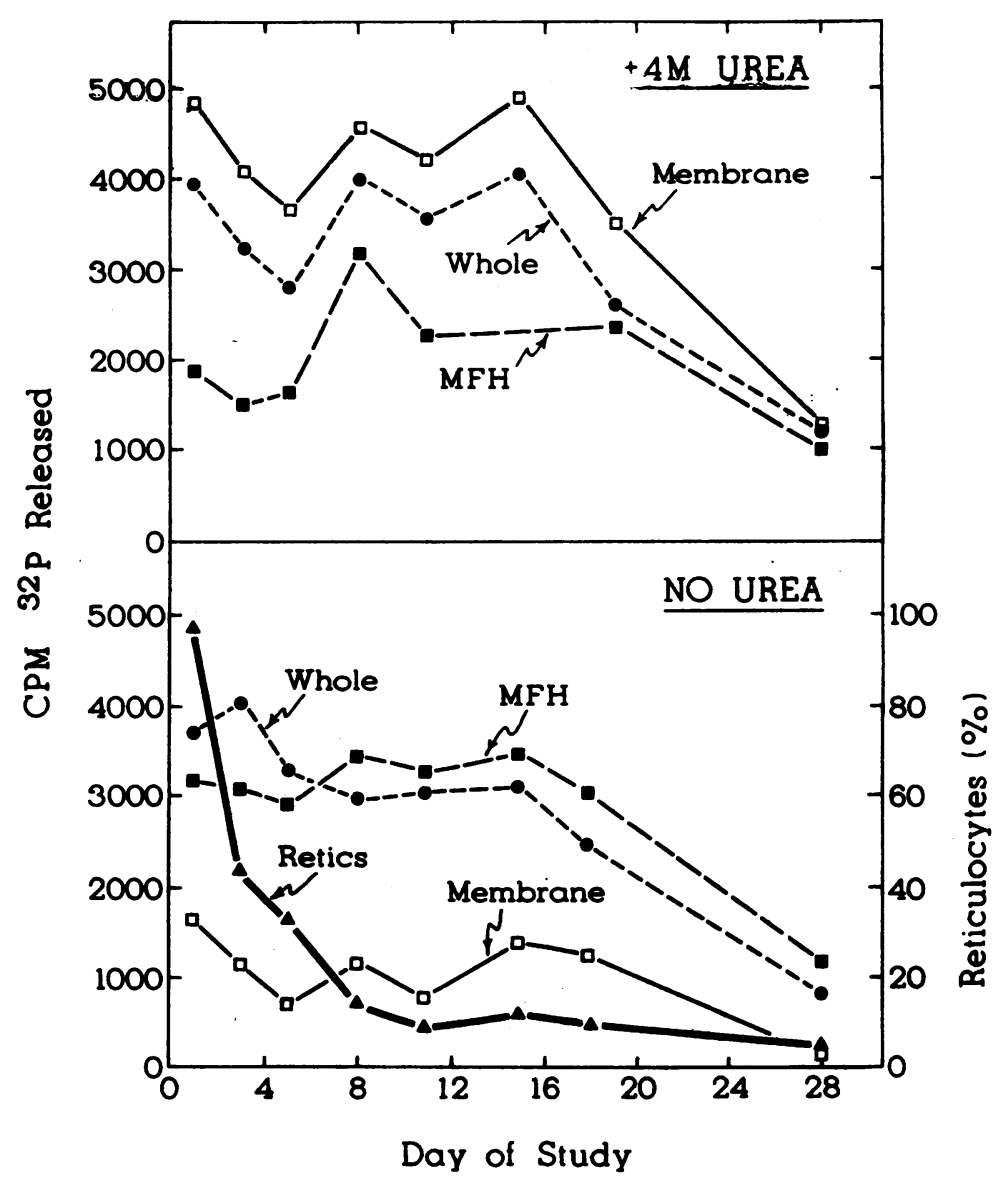

FIGURE 5 The RNase activity of erythroid cell components of a progressively aging population of cells in the absence (lower) and presence (upper) of $4 \mathrm{M}$ urea. The assays were carried out as described for Fig. 1 using $80 \mu \mathrm{g} / \mathrm{ml}$ of ${ }^{2} \mathrm{P}$ total RNA as the substrate. The heavy line in the lower panel depicts the fall in reticulocytosis from $96 \%$ at the beginning of the study to $4 \%$ at the conclusion.

malian erythroid cell. This finding is consistent with the fact that erythroid cell membranes in themselves degrade RNA at a rate greater than that of membrane-free hemolysates (7). The requirement for activation of the membrane-associated RNase, most of which exists in a latent form and which can be activated by exposure to urea, may explain the failure of other investigators to emphasize the cell membrane as a site of erythroid cell RNase activity $(5,18,19)$. Another erythroid cell enzyme, 2,3diphosphoglycerate phosphatase, is also localized to the cell membrane in a latent state, requiring exposure to hyposulfite in order to exhibit maximum activity (20). RNase is found in the limiting membrane of cell lines other than erythroid cells. An endonuclease, capable of degrading viral RNA, has been isolated from the cell wall of Krebs ascites cells (21) and a latent RNase, also activated by urea, is associated with the protoplasmic membrane of $E$. coli (22). The presence of RNase in the limiting membranes of both mammalian and bacterial cells suggests that this structure may have a general role in cellular nucleic acid metabolism.

The localization of enzymes to the erythroid cell membrane appears to be related to their specific metabolic function in the cell. The ATPase system, concerned with the active transport of sodium and potassium across the plasma membrane, and other enzymes involved in membrane transport are located in the cell membrane (23, 24). Enzymes within the erythroid cell membrane are organized in a specific manner (24). For example, an acid phosphatase associated with the rabbit erythroid cell membrane is oriented towards the outer surface of the cell (25) and the active sites of glyceraldehyde phosphate dehydrogenase are oriented towards the cell interior (24). This intramembrane organization appears to have functional significance in terms of substrate availability. The experiments reported here with intact erythroid cells 
suggest that RNase activity is absent from the exterior surface of the erythroid cell. The orientation of the active sites of membrane-associated RNase towards the erythroid cell interior would not be surprising, from a functional viewpoint, since the enzyme participates in intracellular RNA metabolism. It has been suggested, however, that an orientation of membrane-associated RNase to the outer surface of the mammalian cells may serve as a defense mechanism in neutralizing RNA viruses (21). The presence of significant amounts of RNase in the mature erythroid cell, which does not contain RNA (1-4), could possibly be related to a similar defense mechanism. Whether erythroid cell RNase is able to neutralize viruses which attack the red cell has not yet been determined.

The solubilization and activation of membrane RNase by urea, a compound known to modify protein structure (14), suggest that active enzyme sites might be physically shielded by membrane structures. The exact method by which erythroid cell RNase is bound to the cell membrane is obscure, but the presence of enzyme activity in washed membranes following $24 \mathrm{hr}$ of incubation suggests that the attachment is relatively strong. Some bound enzyme is released merely by centrifuging the membranes in a hypotonic phosphate buffer, but maximal release and activation is achieved by exposure to urea. Although urea does alter the susceptibility of substrate RNA to degradation, the data show that the major effect of urea is to activate RNase. It is not possible to state whether solubilization of a bound enzyme is the only manner by which urea activates erythroid cell RNase. Although 2,3-diphosphoglycerate phosphatase, which is bound to the human erythroid cell membrane (20), and the membrane-bound acid phosphatase in rabbit cells (25) appear to be isoenzymes with different characteristics than the corresponding soluble enzymes in the cells, the properties of membrane-associated RNase in the rabbit reticulocyte are almost identical with those of the soluble enzyme found in the membrane-free hemolysate. This suggests that only one type of RNase is present within the erythroid cell. The approximately equal rate of disappearance of both latent RNase activity and total RNase activity as the erythroid cell matures is consistent with this interpretation. Proof of this premise, however, must await detailed studies of the physicochemical properties of the isolated enzymes.

The localization of RNase to the membrane does, however, modify certain characteristics of enzyme activity. It provides a degree of stability to the enzyme, as indicated by the failure of membranes to lose RNase activity during prolonged incubation at $37^{\circ} \mathrm{C}$. The association of erythroid cell RNase with the cell membrane is also in some way particularly involved in the degradation of ribosomes, the particulate form in which most of the cell RNA exists (26). Previous studies have demonstrated that in erythroid cell lysates ribosomes are less susceptible than soluble RNA to enzymatic degradation (6), while during maturation of the intact erythroid cell ribosomes disappear at a greater rate than soluble RNA (7). The apparent conflict between these in vitro and in vivo findings must be related to conditions peculiar to the organization of the cell. One can only speculate as to the reason for the localization of RNase to the rabbit erythroid cell membrane. It is known, however, that $17 \%$ of the total cell complement of ribosomes is associated with the cell membrane (26). The localization of a large amount of RNase to the same site suggests that physical proximity of ribosomes and RNase in the cell membrane may play a part in producing the more rapid degradation of ribosomes, in comparison to soluble RNA, which occurs as the intact erythroid cell matures. Thus, the presence of RNase in the cell membrane, even if only related to the quantity of RNase at that site, may have important functional significance, as is true with enzymes involved in membrane transport.

The erythroid cell membrane participates in many metabolic activities other than transport functions. The presence of RNase in the erythroid cell membrane adds to the evidence that this structure has an active role in cellular nucleic acid metabolism. RNA and ribosomes are closely bound to the cell membrane $(9,26,27)$ and the cell membrane in itself can synthesize protein (28) and degrade RNA (7). Disruption of the functional and structural integrity of the reticulocyte membrane is accompanied by a reversible breakdown of cytoplasmic polyribosomes (8) indicating that membrane alterations can affect protein synthesis in the cell interior. Further studies will be necessary to precisely define the role of the cell membrane in moderating the rate of cellular protein synthesis. It is clear, however, that one means by which this can be done is through the role of the cell membrane in RNA degradation.

\section{ACKNOWLEDGMENTS}

The expert technical assistance of Mrs. Eva Hennel and Mrs. Virginia Johnston is gratefully acknowledged.

This work was supported by U. S. Public Health Service Grant AM HE 13431.

\section{REFERENCES}

1. Grasso, J. A., J. W. Woodward, and H. Swift. 1963. Cytochemical studies of nucleic acids and proteins in erythrocytic development. Proc. Nat. Acad. Sci. U. S. A. 50: 134.

2. Rifkind, R. A., D. Danon, and P. A. Marks. 1964. A1terations in polyribosomes during erythroid cell maturation. J. Cell Biol. 22: 599.

3. Grasso, J. A., H. Swift, and G. A. Ackerman. 1962. Observations on the development of erythrocytes in mammalian fetal liver. J. Cell Biol. 14: 235. 
4. Marks, P. A., and J. S. Kovach. 1966. Development of mammalian erythroid cells. Current Topics in Developmental Biology. 1: 213.

5. Farkas, W., and P. A. Marks. 1968. Partial purification and properties of a ribonuclease from rabbit reticulocytes. J. Biol. Chem. 243: 6464.

6. Burka, E. R. 1969. RNase activity in erythroid cell lysates. J. Clin. Invest. 48: 1724.

7. Burka, E. R. 1969. Characteristics of RNA degradation in the erythroid cell. J. Clin. Invest. 48: 1266.

8. Freedman, M. L., M. Hori, and M. Rabinovitz. 1967. Membranes in polyribosome formation by rabbit reticulocytes. Science (Washington). 157: 323.

9. Schreml, W., and E. R. Burka. 1968. Properties of membrane-bound ribosomes in reticulocytes. J. Biol. Chem. 243: 3573

10. Nilsson, O., and G. Ronquist. 1969. Enzyme activities and ultrastructure of a membrane fraction from human erythrocytes. Biochim. Biophys. Acta. 183: 1.

11. DeBellis, R. H., N. Gluck, and P. A. Marks. 1964. Synthesis of ribonucleic acid in rabbit blood cells in vivo. J. Clin. Invest. 43: 1329.

12. Bray, G. A. 1960. A simple efficient liquid scintillator for counting aqueous solutions in a liquid scintillation counter. Anal. Biochem. 1: 279.

13. Elson, D. 1959. Latent enzymic activity of a ribinucleoprotein isolated from Escherichia coli. Biochim. Biophys. Acta. 36: 372.

14. Kauzmann, W. 1954. Denaturation of proteins and enzymes. In Symposium on the Mechanism of Enzyme Action. W. D. McElroy and B. Glass, editors. Johns Hopkins Press, Baltimore. 70.

15. Dodge, J. T., C. Mitchell, and D. J. Hanahan. 1963. The preparation and chemical characteristics of hemoglobin-free ghosts of human erythrocytes. Arch. Biochem. Biophys. 100: 119 .

16. Rajagopalan, K. V., I. Fridovich, and P. Handler. 1961. Competitive inhibition of enzyme activity by urea. $J$. Biol. Chem. 236: 1059.
17. Borsook, H., J. B. Lingrel, J. L. Scari, and R. L. Millette. 1962. Synthesis of haemoglobin in relation to the maturation of erythroid cells. Nature (London). 196: 347 .

18. Rowley, P. T., and F. Barnes. 1966. A reticulocyte RNAse activity declining with cell maturation. Fed. Proc. 25: 645 .

19. Stavy, L., M. Feldman, and D. Elson. 1964. On ribonuclease activity in reticulocyte ribosomes. Biochim. Biophys. Acta. 91: 606.

20. Schröter, W., and M. Neuvians. 1970. Membrane-bound 2,3-diphosphoglycerate phosphate of human erythrocytes. J. Membrane Biol. 2: 31.

21. Stonehill, E. H., and J. Huppert. 1968. Ribonuclease activity associated with mammalian cell walls. Biochim. Biophys. Acta. 155: 353.

22. Neu, H. C., and L. A. Heppel. 1964. Some observations on the latent" ribonuclease of Escherichia coli. Proc. Nat. Acad. Sci. U. S. A. 51: 1267.

23. Post, R. L., C. R. Merritt, C. R. Kinsolving, and D. C. Albright. 1960. Membrane adenosine triphosphatase as a participant in the active transport of sodium and potassium in the human erythrocyte. J. Biol. Chem. 235: 1796.

24. Schrier, S. L. 1966. Organization of enzymes in human erythrocyte membranes. Amer. J. Physiol. 210: 139.

25. Berry, D. H., and P. Hochstein. 1969. Membrane acid phosphatase in rabbit erythrocytes. Arch. Biochem. Biophys. $131: 170$.

26. Burka, E. R. 1968. The distribution of RNA and ribosomes in reticulocytes. Biochim. Biophys. Acta. 166: 672.

27. Burka, E. R., W. Schreml, and C. J. Kick. 1967. Membrane-bound ribonucleic acid in mammalian erythroid cells. Biochemistry. 6: 2840.

28. Kruh, J. 1968. Biosynthèse d'hémoglobine par des préparations de membranes de reticulocytes. Biochim. Biophys. Acta. 169: 511. 